NASA/TM-2010-216927

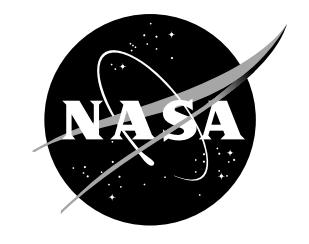

\title{
The Reduction of Lunar Regolith by Carbothermal Processing Using Methane
}

R. Balasubramaniam

National Center for Space Exploration Research, Glenn Research Center, Cleveland, Ohio

S.A. Gokoglu

Glenn Research Center, Cleveland, Ohio

U. Hegde

National Center for Space Exploration Research, Glenn Research Center, Cleveland, Ohio 


\section{NASA STI Program . . . in Profile}

Since its founding, NASA has been dedicated to the advancement of aeronautics and space science. The NASA Scientific and Technical Information (STI) program plays a key part in helping NASA maintain this important role.

The NASA STI Program operates under the auspices of the Agency Chief Information Officer. It collects, organizes, provides for archiving, and disseminates NASA's STI. The NASA STI program provides access to the NASA Aeronautics and Space Database and its public interface, the NASA Technical Reports Server, thus providing one of the largest collections of aeronautical and space science STI in the world. Results are published in both non-NASA channels and by NASA in the NASA STI Report Series, which includes the following report types:

- TECHNICAL PUBLICATION. Reports of completed research or a major significant phase of research that present the results of NASA programs and include extensive data or theoretical analysis. Includes compilations of significant scientific and technical data and information deemed to be of continuing reference value. NASA counterpart of peer-reviewed formal professional papers but has less stringent limitations on manuscript length and extent of graphic presentations.

- TECHNICAL MEMORANDUM. Scientific and technical findings that are preliminary or of specialized interest, e.g., quick release reports, working papers, and bibliographies that contain minimal annotation. Does not contain extensive analysis.

- CONTRACTOR REPORT. Scientific and technical findings by NASA-sponsored contractors and grantees.
- CONFERENCE PUBLICATION. Collected papers from scientific and technical conferences, symposia, seminars, or other meetings sponsored or cosponsored by NASA.

- SPECIAL PUBLICATION. Scientific, technical, or historical information from NASA programs, projects, and missions, often concerned with subjects having substantial public interest.

- TECHNICAL TRANSLATION. Englishlanguage translations of foreign scientific and technical material pertinent to NASA's mission.

Specialized services also include creating custom thesauri, building customized databases, organizing and publishing research results.

For more information about the NASA STI program, see the following:

- Access the NASA STI program home page at http://www.sti.nasa.gov

- E-mail your question via the Internet to help@ sti.nasa.gov

- Fax your question to the NASA STI Help Desk at $443-757-5803$

- Telephone the NASA STI Help Desk at 443-757-5802

- Write to: NASA Center for AeroSpace Information (CASI) 7115 Standard Drive Hanover, MD 21076-1320 
NASA/TM-2010-216927

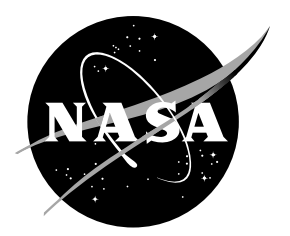

\section{The Reduction of Lunar Regolith by Carbothermal Processing Using Methane}

R. Balasubramaniam

National Center for Space Exploration Research, Glenn Research Center, Cleveland, Ohio

S.A. Gokoglu

Glenn Research Center, Cleveland, Ohio

U. Hegde

National Center for Space Exploration Research, Glenn Research Center, Cleveland, Ohio

National Aeronautics and

Space Administration

Glenn Research Center

Cleveland, Ohio 44135 


\section{Acknowledgments}

The authors would like to thank K. Sacksteder and D. Linne of NASA Glenn Research Center and R. Gustafson and B. White of Orbitec, Madison, Wisconsin, for discussions and comments during the course of the investigation. Support for this work was obtained from the In-Situ Resource Utilization (ISRU) project which is a part of the NASA Exploration Technology Development Program, for which we are grateful.

Level of Review: This material has been technically reviewed by technical management.

Available from

NASA Center for Aerospace Information 7115 Standard Drive

Hanover, MD 21076-1320
National Technical Information Service 5301 Shawnee Road Alexandria, VA 22312

Available electronically at http://gltrs.grc.nasa.gov 


\title{
The Reduction of Lunar Regolith by Carbothermal Processing Using Methane
}

\author{
R. Balasubramaniam \\ National Center for Space Exploration Research \\ Glenn Research Center \\ Cleveland, Ohio 44135 \\ S.A. Gokoglu \\ National Aeronautics and Space Administration \\ Glenn Research Center \\ Cleveland, Ohio 44135 \\ U. Hegde \\ National Center for Space Exploration Research \\ Glenn Research Center \\ Cleveland, Ohio 44135
}

\begin{abstract}
The processing of lunar regolith for the production of oxygen is a key component of the In-Situ Resource Utilization plans currently being developed by NASA. In the carbothermal process, a portion of the surface of the regolith in a container is heated by exposure to a heat source so that a small zone of molten regolith is established. A continuous flow of methane is maintained over the molten regolith zone. In this paper, we discuss the development of a chemical conversion model of the carbothermal process to predict the rate of production of carbon monoxide. Our model is based on a mechanism where methane pyrolyzes when it comes in contact with the surface of the hot molten regolith to form solid carbon and hydrogen gas. Carbon is deposited on the surface of the melt, and hydrogen is released into the gas stream above the melt surface. We assume that the deposited carbon mixes in the molten regolith and reacts with metal oxides in a reduction reaction by which gaseous carbon monoxide is liberated. Carbon monoxide bubbles through the melt and is released into the gas stream. It is further processed downstream to ultimately produce oxygen.
\end{abstract}

Keywords: Carbothermal processing, lunar regolith, pyrolysis, kinetics

PACS: $47.70 . \mathrm{Fw}, 82.40 .-\mathrm{g}$ 


\section{NOMENCLATURE}

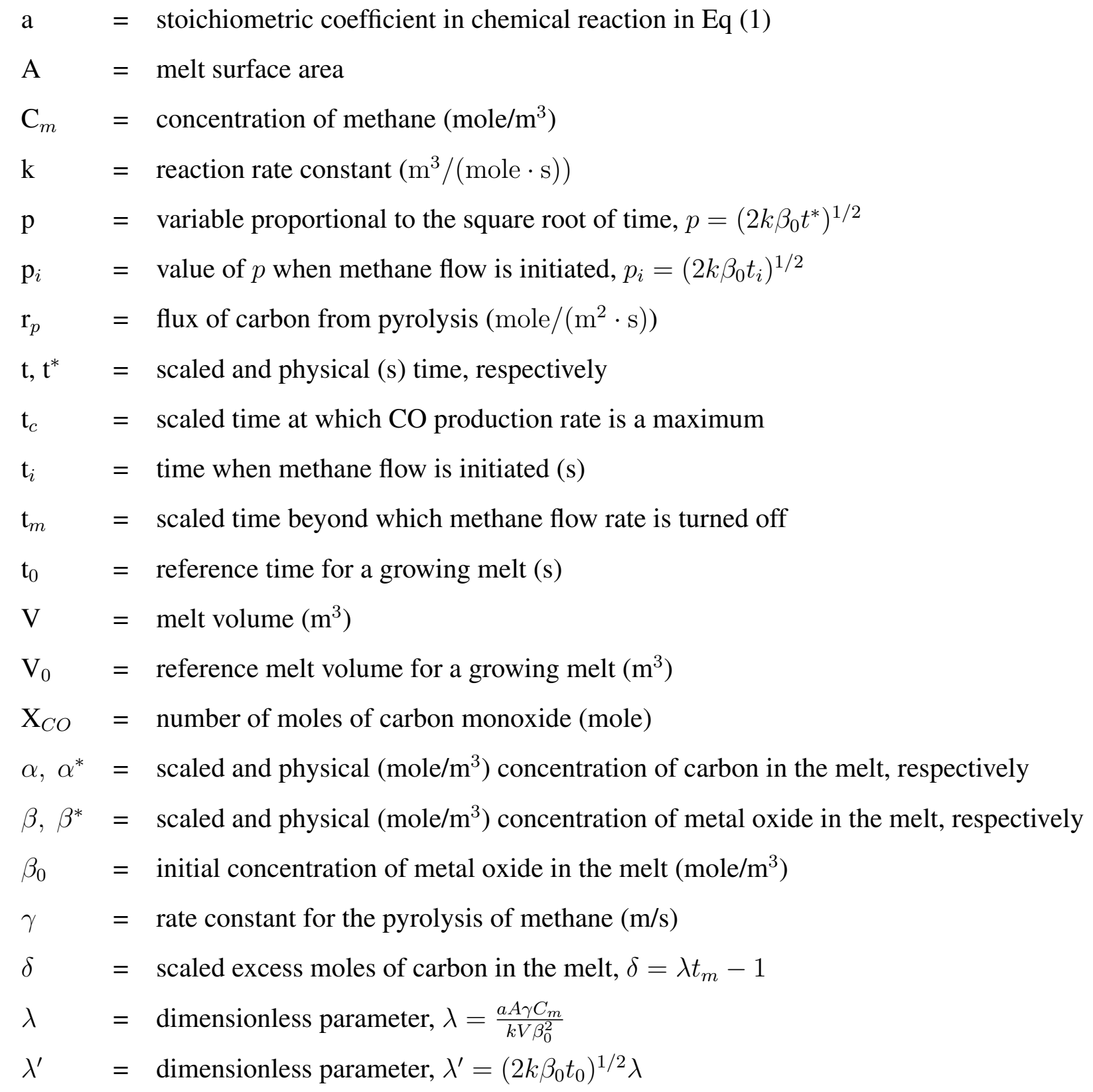

\section{Introduction}

NASA's plans for lunar exploration involves the production of oxygen for life support and use as a propellant. Oxygen is available in the lunar regolith as oxides of various materials. The extraction of gaseous oxygen from the oxides by reduction using hydrogen (Taylor and Carrier, 1992), molten salt electrolysis (Tripuraneni-Kilby et al., 2006) and carbothermal processing of 
regolith (ORBITEC, 2006) are currently being pursued by NASA (Sanders et al., 2008), and is a prime candidate for In-Situ Resource Utilization.

Carbothermal processing refers to the use of carbon in some form, together with high processing temperature, to reduce the oxides. Examples of carbothermal processes on Earth are the production of silicon from silica using wood, charcoal or coal (a standard process), and the production of titanium-rich materials by refining low-grade ilmenites using graphite (Wang and Yuan, 2006).

The carbothermal processing of lunar regolith using methane as the source for carbon was first performed by Rosenberg and co-workers at Aerojet in the 1960's (Rosenberg et al., 1991). It has been revisited by researchers at Orbital Technologies Corporation (ORBITEC) since the early 1990's. An excellent reference and resource for the application of the carbothermal process for the conversion of lunar regolith to ultimately produce oxygen is a report by ORBITEC (ORBITEC, 2006; see also Gustafson, White and Fidler, 2009). ORBITEC used lunar regolith simulants in their processing experiments.

Figure 1 shows a schematic sketch of the carbothermal reactor. Lunar regolith is contained in a suitable container. A portion of the surface of the regolith is heated by exposure to a heat source such as a laser beam or a concentrated solar heat flux, so that a small zone of molten regolith is established within the container. The unmelted regolith surrounding the molten zone thermally insulates it from the container. A heat shield is used above the molten zone to minimize radiative heat loss. A continuous flow of methane is maintained over the molten regolith zone. Since the molten regolith is very hot (temperature will exceed $1650^{\circ} \mathrm{C}$ ), methane will pyrolyze when it contacts the molten zone. Carbon is deposited on the surface of the melt, and hydrogen is released into the gas phase above the melt surface. The deposited carbon reacts with metal oxides (chiefly $\mathrm{SiO}_{2}$ ) in the molten regolith in a reduction reaction in which carbon monoxide is liberated. $\mathrm{CO}$ bubbles through the melt and is released in the gas phase above the melt. It is carried downstream for further chemical processing to ultimately yield oxygen, which is liquified and stored. Our objective is to model the production of carbon monoxide in the carbothermal reactor, and predict the rate at which $\mathrm{CO}$ is liberated as a function of the various physicochemical parameters of the system. We also pursue simple strategies to control the buildup of carbon in the melt. 


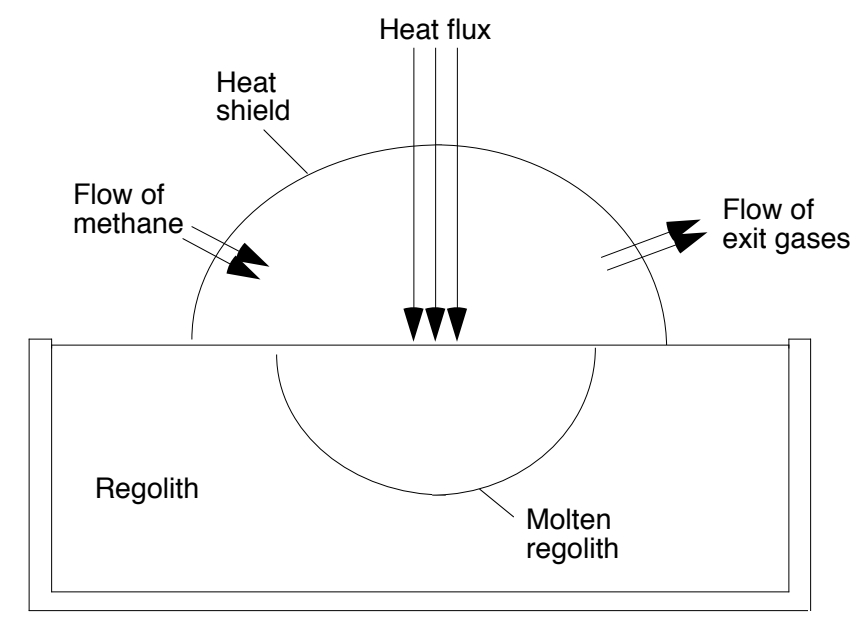

FIGURE 1: Sketch of the Carbothermal Reduction of Lunar Regolith.

\section{Model formulation and assumptions}

We assume that carbon deposition occurs on the hot molten surface via a surface reaction. This surface reaction is regarded as first order with respect to a gaseous carbon-containing species and produces solid carbon and gaseous hydrogen. This carbon-containing species need not necessarily be methane; it can be some other carboneous species which may be produced by the gas-phase pyrolysis of methane. In reality, depending on the operating pressure, flow conditions and temperature profiles above the hot molten surface, there would be a distribution of carbon-containing species (e.g., methane, ethylene, acetylene, methyl radical, etc.,) and each of them would react on the surface to deposit carbon at their own rates. Our model, however, "lumps" all of these possibilities into a "single" species and describes the deposition process by a first-order surface reaction of this "predominant" species. For sake of simplicity, we call this "lumped" species methane throughout the paper. Thus, the flux of carbon deposited on the surface of the melt is assumed to be proportional to the concentration of methane in the gas phase adjacent to the melt surface.

We assume that the rate of transport of gaseous species from the bulk flow to the melt surface is not limiting the surface reaction rate. This is expected to be valid in the practical application, where the goal would be to maximize the carbon deposition rate so that the $\mathrm{CO}$ production rate 
is maximized. This can be accomplished by an ample and continuous supply of methane in the bulk flow so that its rate of diffusion through the boundary layer above the melt surface is sufficiently fast to replenish its consumption at the surface. Under these conditions, the concentration of methane at the surface can be assumed to be constant and approximated by its value at the flow inlet. The surface reaction rate constant needs to be extracted by direct comparison of model predictions with experimental data. The analysis can easily be extended to situations where gas-phase transport effects are significant.

The deposited carbon is assumed to be 'well-mixed' in the melt such that there are no spatial gradients of the concentration of carbon or the metal oxide within the melt. This would be the case when the zone is sufficiently small such that diffusion of carbon within the melt is rapid relative to the time of its reaction with the metal oxide. Mixing is more likely caused by temperature gradients in the melt that generate a flow due to natural convection and thermocapillary forces. Besides, the reaction in the melt liberates gaseous carbon monoxide in it, and the gravity-induced bubble motion is likely to render the melt to be well-mixed. The melt viscosity is expected to play a significant role in determining the relative rates of carbon advection and diffusion. Heiken et al. (1991) mention that a synthetic liquid with the composition of a lunar basalt sampled by Apollo 11 has a viscosity in the range 4.5 poise $\left(1495^{\circ} \mathrm{C}\right)$ to 10 poise $\left(1395^{\circ} \mathrm{C}\right)$ and that terrestrial lavas are ten times more viscous. The viscosity of melts typically depends on the processing temperature and composition, in particular the proportion of $\mathrm{MgO}, \mathrm{CaO}, \mathrm{FeO}$ and $\mathrm{Fe}_{3} \mathrm{O}_{4}$, etc., in comparison with those of $\mathrm{SiO}_{2}$ and $\mathrm{Al}_{2} \mathrm{O}_{3}$ (Themelis, 1995).

The carbon in the melt is assumed to undergo a single-step, first-order chemical reaction with the metal oxide present in the molten regolith. This reaction rate constant also needs to be determined by comparison of the model predictions with experimental data. We assume that the deposited carbon does not form a crust on the surface of the melt, shielding the melt surface from the heat flux and the methane flow. While crusting has been observed under some conditions (ORBITEC 2006), rapid mixing due to bubble evolution and controlled rate of deposition of carbon greatly diminishes the likelihood of crust formation. 
We assume that the molten zone is established and maintained by heating the regolith by suitable means, in a batch-processing mode. The heat transfer aspects of the problem are not analyzed here. The processes of chemical conversion and heat transfer within the molten regolith are assumed to be uncoupled. Let $V$ and $A$ denote the volume and the surface area of the molten zone of regolith. $A$ is assumed to be constant and independent of time during the chemical conversion process. We will analyze cases where the melt volume $V$ is (i) a constant independent of time, and (ii) increases as the square root of time. A constant melt volume implies that the molten regolith fully occupies a fixed volume of its container (the regolith shown in Figure 1 is fully molten and the container is in contact with the melt). It might also be applied for a case where the heat transfer process is such that $V$ and $A$ are slowly varying in time compared to the time scale for chemical conversion. When there is contact between the melt and the solid regolith particles, we assume that there is a well-defined interface demarcating the melt and the solid regolith particles. Thus no trickling of the melt into the regolith bed is considered. This assumption appears to be true in the experiments of Gustafson et al. (2009) where they report their post-experiment observation of only loose binding of the regolith particles to a solidified molten mass.

The analysis is organized as follows. We first consider $V$ to be constant, and determine the evolution of the concentration of carbon and metal oxide in the melt. This is followed by an analysis of a possible strategy to minimize the amount of leftover carbon in the melt. Finally, a growing melt where $V$ increases as the square root of time, for constant $A$, is also analyzed.

Let $\alpha^{*}$ and $\beta^{*}$ denote the molar concentration $\left(\right.$ moles $/ \mathrm{m}^{3}$ ) of carbon and metal oxide, respectively, within the melt. At time $t^{*}=0$, the initial concentrations are $\alpha^{*}=0$ and $\beta^{*}=\beta_{0}$. The chemical reaction between carbon and the metal oxide in the regolith is

$$
a M O_{x}+C \Leftrightarrow C O+a M
$$

The stoichiometric coefficient of the oxide term in the above reaction is $a=1 / x$. We assume that the chemical reaction is first order with respect to carbon and the metal oxide, with a rate constant $k\left(\mathrm{~m}^{3} /(\right.$ moles $\left.\cdot \mathrm{s})\right)$. The flux of carbon due to pyrolysis of methane is denoted by $r_{p}$, and is assumed to be linearly proportional to the molar concentration of methane $C_{m}$ in the gas 
phase adjacent to the melt surface, with the constant of proportionality denoted by $\gamma(\mathrm{m} / \mathrm{s})$. The equations for the evolution of $\alpha^{*}$ and $\beta^{*}$ in the melt can be obtained from mass conservation to be:

$$
\begin{gathered}
\frac{d \alpha^{*}}{d t^{*}}=\frac{A \gamma C_{m}}{V}-k \alpha^{*} \beta^{*}, \\
\frac{d \beta^{*}}{d t^{*}}=-a k \alpha^{*} \beta^{*} .
\end{gathered}
$$

The instantaneous rate of production of carbon monoxide is

$$
\frac{d X_{C O}}{d t^{*}}=-\frac{V}{a} \frac{d \beta^{*}}{d t^{*}}
$$

\section{Results and Discussion}

\subsection{Constant melt volume}

We assume that the melt area and volume are constant. The methane concentration $C_{m}$ in the gas phase is also assumed to be constant. Dimensionless variables are defined as follows.

$$
\alpha=\frac{\alpha^{*}}{\beta_{0} / a}, \quad \beta=\frac{\beta^{*}}{\beta_{0}}, \quad t=\frac{t^{*}}{1 /\left(k \beta_{0}\right)} .
$$

The scaled equations and boundary conditions are

$$
\begin{gathered}
\frac{d \alpha}{d t}=\lambda-\alpha \beta \\
\frac{d \beta}{d t}=-\alpha \beta \\
\alpha(0)=0, \quad \beta(0)=1
\end{gathered}
$$

where $\lambda=\frac{a A \gamma C_{m}}{k V \beta_{0}^{2}}$ is a dimensionless parameter. $\lambda$ is a measure of the relative importance of the rate of production of carbon by the surface pyrolysis of methane to its rate of consumption by reaction with the metal oxide. The former rate is constant for typical operating conditions of fixed temperature, pressure, and sufficient flow rate to maintain a constant methane concentration. The latter rate varies depending on the accumulation or depletion of carbon and the availability of the 
metal oxide in the melt. So, the magnitude of $\lambda$ indicates the relative dominance of the two rates in a competitive process; i.e., small lambda means relatively small carbon deposition rates, and vice versa.

Equation (4) for the instantaneous rate of production of carbon monoxide can be expressed as

$$
\frac{d X_{C O}}{d t^{*}}=\frac{V k \beta_{0}^{2}}{a} \alpha \beta
$$

Thus the instantaneous rate of production of carbon monoxide is proportional to the product of $\alpha$ and $\beta$. The solution can be determined to be

$$
\begin{gathered}
\alpha=\beta-1+\lambda t \\
\beta=\frac{2 \sqrt{\lambda} \operatorname{Exp}\left(t-\frac{\lambda}{2} t^{2}\right)}{2 \sqrt{\lambda}+\operatorname{Exp}\left(\frac{1}{2 \lambda}\right) \sqrt{2 \pi}\left[\operatorname{Erf}\left(\frac{1}{\sqrt{2 \lambda}}\right)+\operatorname{Erf}\left(\frac{t \lambda-1}{\sqrt{2 \lambda}}\right)\right]}
\end{gathered}
$$

The following expression is an asymptotic expansion for $\beta$ that is especially useful for small values of $\lambda$.

$$
\beta=\frac{1-\lambda t}{\left(\lambda-3 \lambda^{2}+\ldots\right)(1-\lambda t) \operatorname{Exp}\left(-t+\frac{\lambda}{2} t^{2}\right)+\left(1-\frac{\lambda}{(1-\lambda t)^{2}}+\frac{3 \lambda^{2}}{(1-\lambda t)^{4}}+\ldots\right)}
$$

Plots of the scaled concentrations of carbon $(\alpha)$ and metal oxide $(\beta)$, and the scaled rate of production of carbon monoxide (which is proportional to the product $\alpha \beta$, see Equation 9) from the solution given above are shown in Figure 2 for various values of $\lambda$. It is worthy of note that, in the simplified model that we have developed, the only parameter that determines the behavior of the reactor is $\lambda$. This parameter captures the effects of melt size relative to its surface area, reaction rate constant, pyrolysis rate constant, and the concentrations of methane and metal oxide on the rate at which chemical conversion takes place in the reactor.

Figure 2 shows that the metal oxide concentration in the melt decreases monotonically with time, and the amount of carbon in the melt increases monotonically with time. The rate of production of carbon monoxide is initially zero and increases with time as the reaction between the deposited 

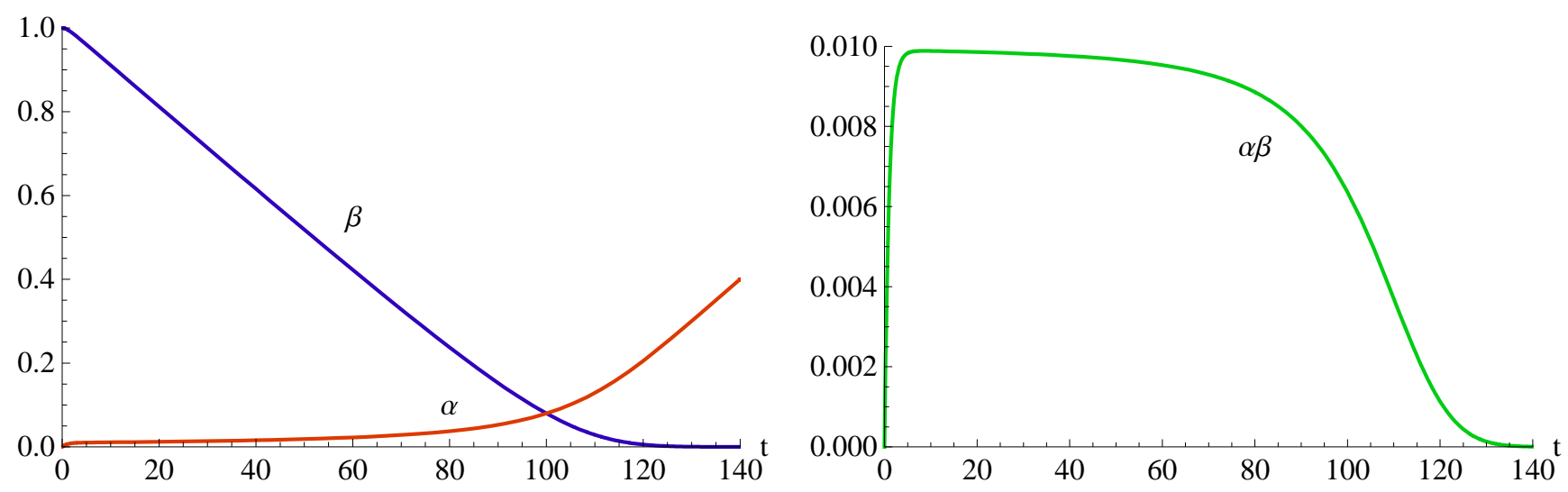

(a) $\lambda=0.01$

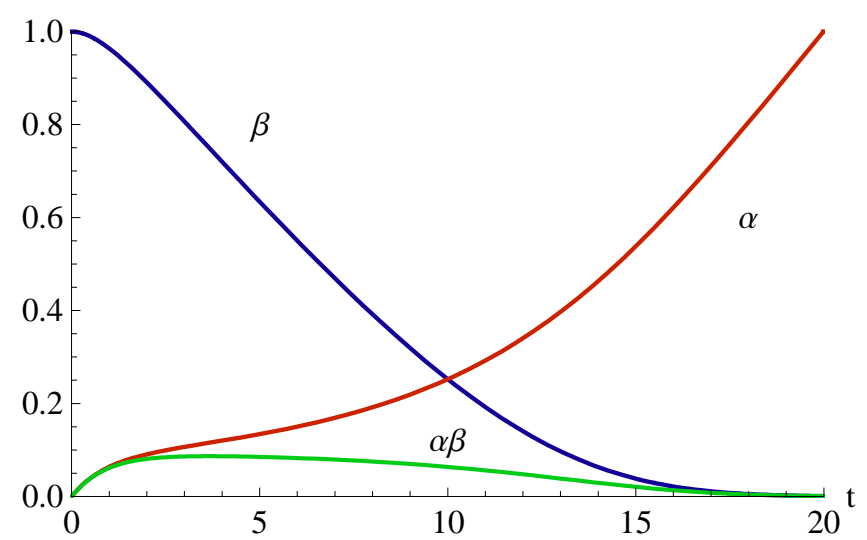

(b) $\lambda=0.1$

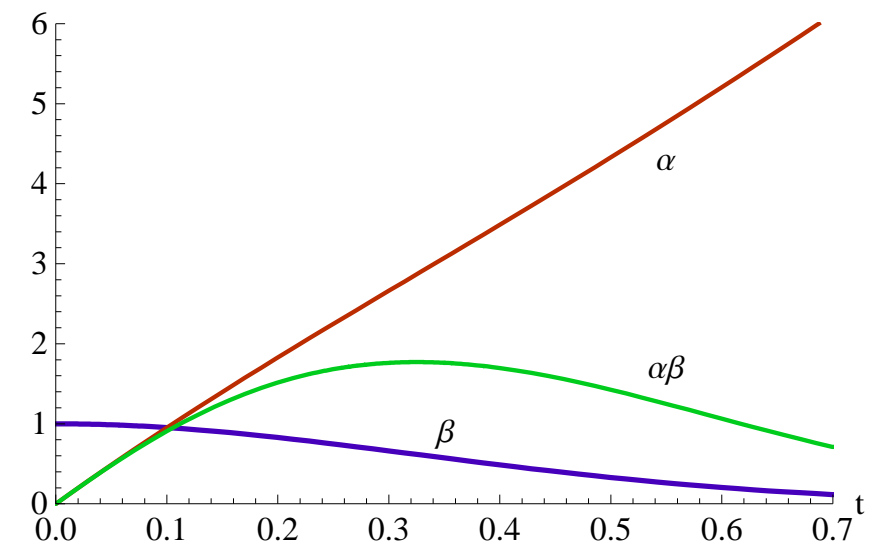

(d) $\lambda=10$

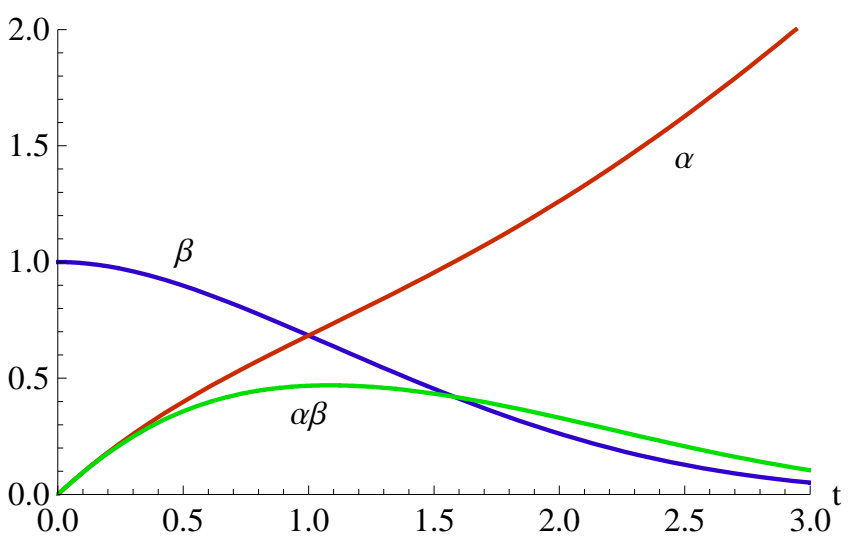

(c) $\lambda=1$ 


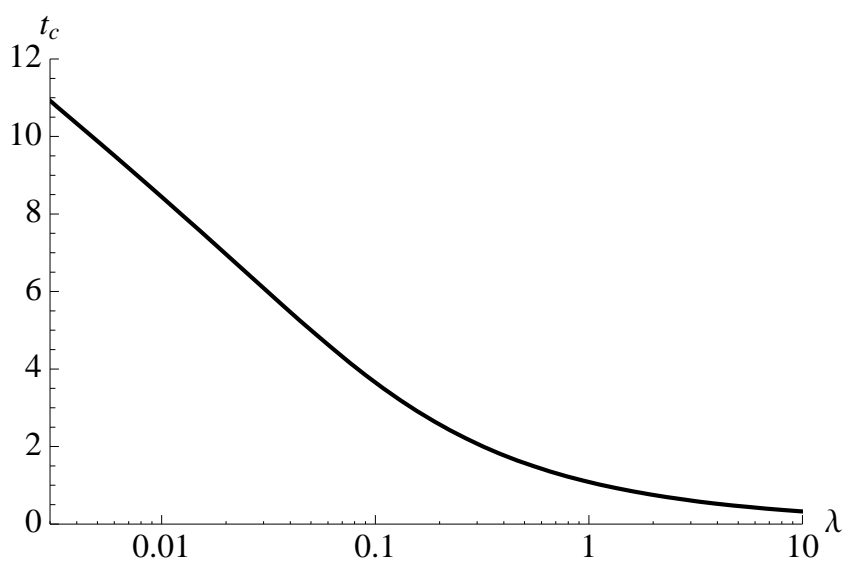

(a)

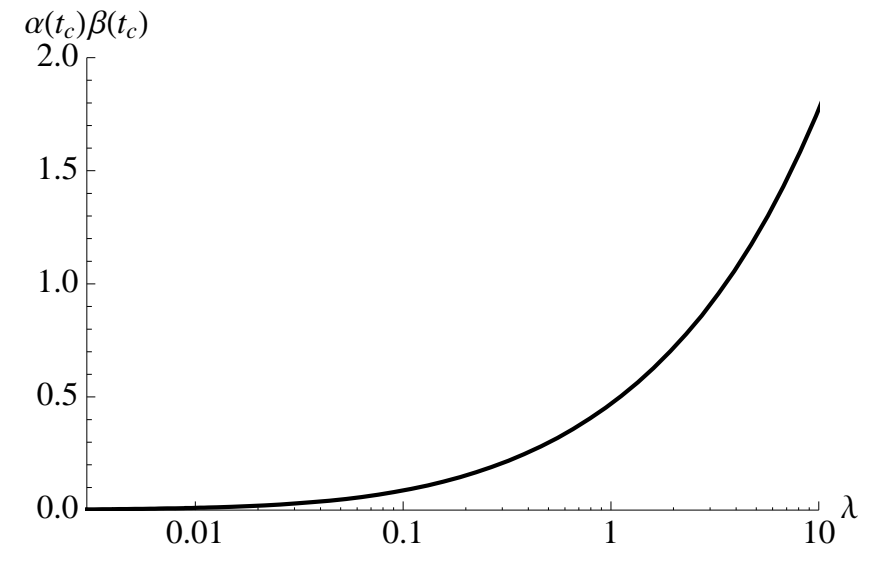

(b)

FIGURE 3: (a) the scaled time $t_{c}$ at which the carbon monoxide production rate is a maximum and (b) the corresponding scaled maximum rate of production of $\mathrm{CO}\left(\alpha\left(t_{c}\right) \beta\left(t_{c}\right)\right)$, both as a function of $\lambda$.

carbon and the metal oxide progresses, and finally decreases to zero as the reaction is completed. The exact shape of the curves in Figure 2, especially that for the the rate of production of CO, is quite sensitive to the value of $\lambda$.

As the metal oxide is depleted, the reaction finally slows down and stops. Figure 2 shows that the rate of production of $\mathrm{CO}$ attains a maximum before it eventually decreases to zero. From Equations (10) and (11), it can be shown that the maximum is attained at a time $t=t_{c}$ which satisfies the following equation.

$$
\beta\left(t_{c}\right)=\frac{3}{4}\left(1-\lambda t_{c}\right)+\left[\frac{1}{16}\left(1-\lambda t_{c}\right)^{2}+\frac{\lambda}{2}\right]^{1 / 2}
$$

$t_{c}$ represents the time for which there is an optimal balance between the accumulation of carbon in the melt due to deposition at the melt surface and its consumption by reaction with the metal oxide. The dependence of $t_{c}$ and the scaled maximum CO production rate $\alpha\left(t_{c}\right) \beta\left(t_{c}\right)$ on $\lambda$ are shown in Figure $3 . t_{c}$ monotonically decreases with increasing $\lambda$, while the scaled maximum $\mathrm{CO}$ production rate is a monotonically increasing function of $\lambda$. The results for $t_{c}$ would be useful in design and operation of the reactor to ensure that requirements on the amount and rate of production of $\mathrm{CO}$ are met, and identify times beyond which there is diminishing returns in operating the reactor. 
Since the amount of carbon in the melt increases with time, there is unreacted carbon that is left behind in the melt after the reaction is completed. A useful strategy to minimize the amount of unreacted carbon is to turn the supply of methane off at an appropriate time before the reaction is completed, such that the residual amount of carbon present in the melt at that time is sufficient to react with the remaining amount of the metal oxide. This scenario is addressed below.

\subsection{Control of carbon in the melt}

It can be seen from Figure 2 that towards the end of the conversion process (for large $t$ ), $\alpha$ is quite large. This represents the large amount of carbon that has been deposited on the surface of the melt. On the other hand, the concentration of metal oxide in the melt is quite low, showing that much of the metal oxide has been converted. Therefore, much of the carbon that has been deposited remains unreacted in the melt. Once the chemical conversion process is terminated after a sufficient amount of the metal oxide in the regolith is converted, the unreacted carbon remains in the spent regolith. It is wasted, unless the spent regolith is specifically processed to recover the carbon. Since carbon (in the form of methane) is envisioned to be transported from Earth to the moon, it is desirable to minimize the carbon loss by minimizing the unreacted carbon in the melt.

One strategy to minimize the carbon loss is by turning the flow of methane off at some point in time before the end of the conversion process. The idea is that the amount of carbon present in the melt at the time the methane flow is turned off is sufficient to react with the residual metal oxide in the melt. Since there is no fresh carbon that is deposited to the melt after the flow of methane is turned off, the steep increase in the amount of carbon in the melt depicted in Figure 2 will be avoided.

By turning the methane flow off, we mean that the concentration of methane in the inlet gas stream is zero. Since there are other sub-systems present downstream of the carbothermal reactor to process the carbon monoxide produced, there must still be gases flowing through the entire system. We anticipate that even with the concentration of methane in the inlet stream to the carbothermal reactor being zero, the gas flow rate through the entire system is maintained by employing other 'sweep' gases (such as hydrogen, carbon monoxide, inert gas, etc.). 
We assume that the methane flow is turned off at $t=t_{0}$. For $t \leq t_{0}$, the solution given in Equations (10) and (11) applies. The chemical conversion for $t>t_{0}$ can be modeled as

$$
\begin{gathered}
\frac{d \alpha}{d t}=-\alpha \beta \\
\frac{d \beta}{d t}=-\alpha \beta \\
\alpha\left(t_{0}\right)=\alpha_{t_{0}}, \quad \beta\left(t_{0}\right)=\beta_{t_{0}}
\end{gathered}
$$

where

$$
\beta_{t_{0}}=\frac{2 \sqrt{\lambda} \operatorname{Exp}\left(t_{0}-\frac{\lambda}{2} t_{0}^{2}\right)}{2 \sqrt{\lambda}+\operatorname{Exp}\left(\frac{1}{2 \lambda}\right) \sqrt{2 \pi}\left[\operatorname{Erf}\left(\frac{1}{\sqrt{2 \lambda}}\right)+\operatorname{Erf}\left(\frac{t_{0} \lambda-1}{\sqrt{2 \lambda}}\right)\right]}
$$

Note that $\alpha_{t_{0}}=\beta_{t_{0}}-1+\lambda t_{0}$. Let $\alpha_{t_{0}}-\beta_{t_{0}}=\lambda t_{0}-1=\delta . \delta$ represents the moles of carbon in the melt in excess of stoichiometry at the time that the methane flow is turned off. The solution to Equations (14) - (16) is

$$
\begin{gathered}
\beta=\frac{\beta_{t_{0}} \delta e^{\delta\left(t_{0}-t\right)}}{\beta_{t_{0}}+\delta-\beta_{t_{0}} e^{\delta\left(t_{0}-t\right)} \quad t \geq t_{0}} \\
\alpha=\delta+\frac{\beta_{t_{0}} \delta e^{\delta\left(t_{0}-t\right)}}{\beta_{t_{0}}+\delta-\beta_{t_{0}} e^{\delta\left(t_{0}-t\right)}} \quad t \geq t_{0}
\end{gathered}
$$

When $\delta=0$ the number of moles of carbon and metal oxide are in stoichiometric balance. The above results may be specialized for $\delta=0$ to

$$
\beta=\alpha=\frac{\beta_{t_{0}}}{1+\beta_{t_{0}}\left(t-t_{0}\right)} \quad t \geq t_{0}
$$

It can be shown that as $t \rightarrow \infty$

$$
\begin{aligned}
& \beta \rightarrow 0, \quad \alpha \rightarrow \delta \text { for } \delta>0 \\
& \beta \rightarrow-\delta, \quad \alpha \rightarrow 0 \text { for } \delta<0 \\
& \beta \rightarrow 0, \quad \alpha \rightarrow 0 \text { for } \delta=0
\end{aligned}
$$



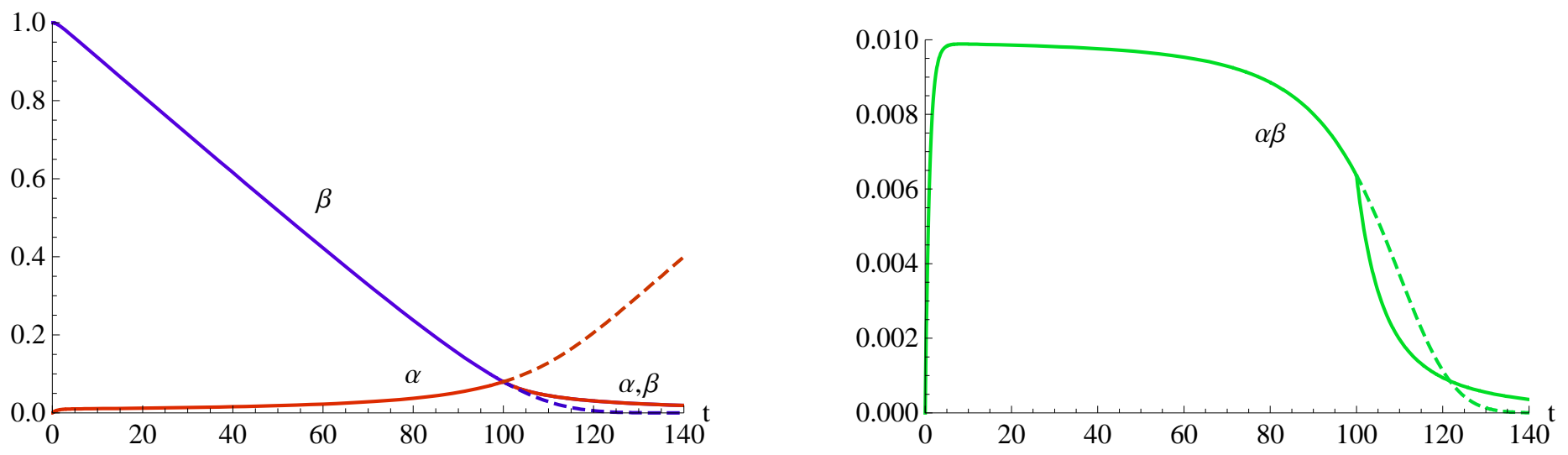

(a) $\lambda=0.01$

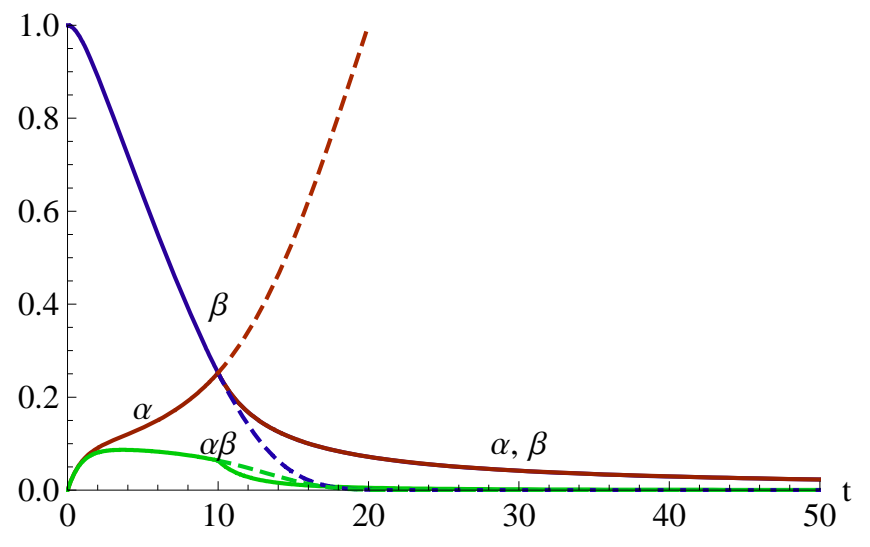

(b) $\lambda=0.1$

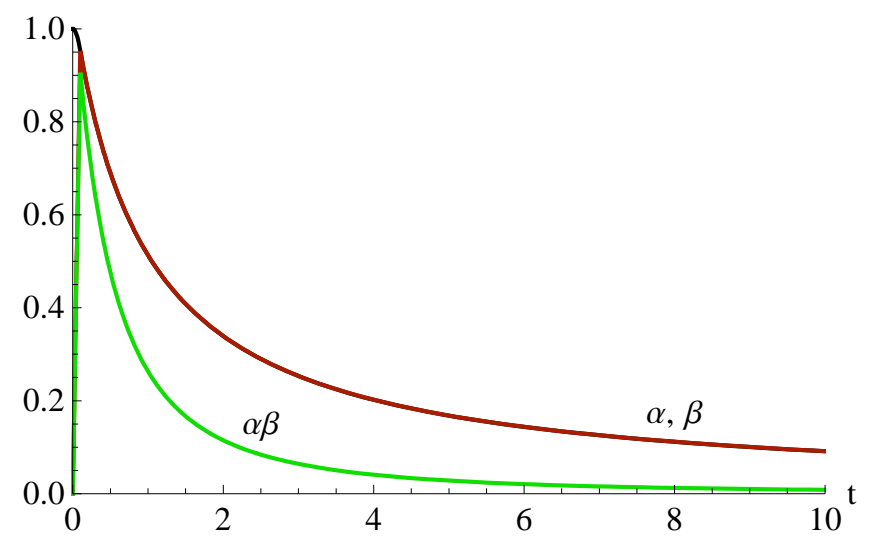

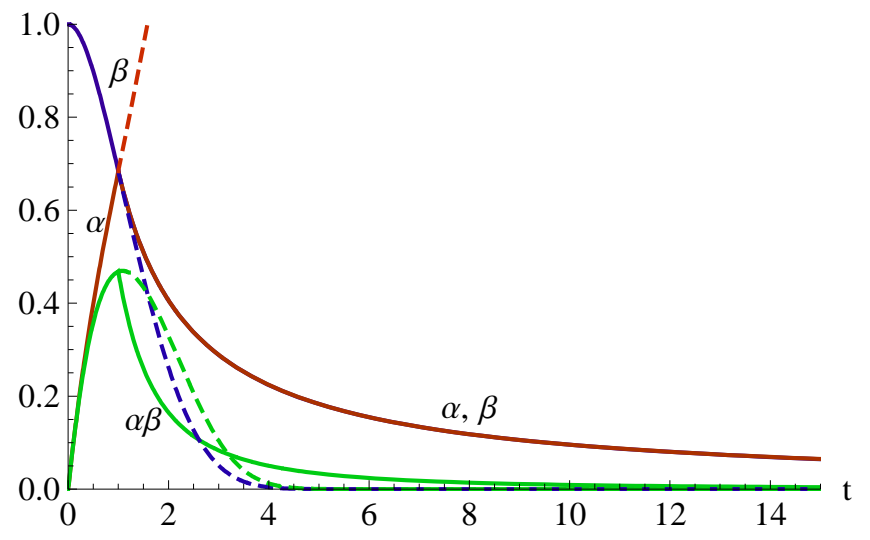

(c) $\lambda=1$

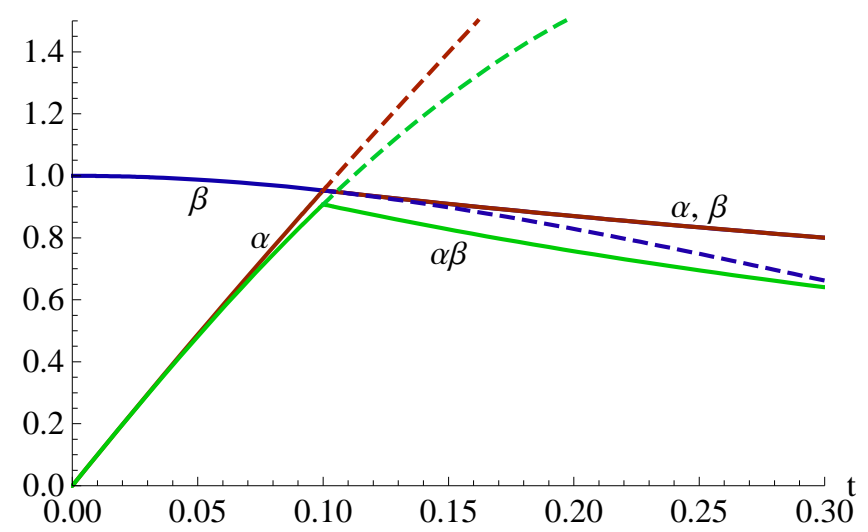

(d) $\lambda=10$ the scaled rate of production of carbon monoxide $(\alpha \beta)$ for various values of $\lambda$, with carbon loss control (solid curves), for a case with $\delta=0$. Methane flow is turned off beyond the time at which the curves for $\alpha$ and $\beta$ intersect. Dashed curves correspond to a case where the methane flow is not turned off (same as in Figure 2). 


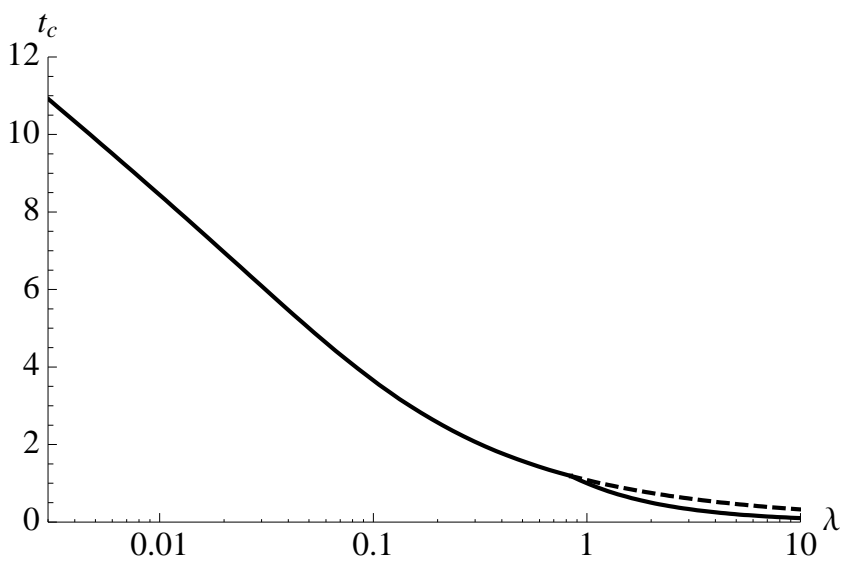

(a)

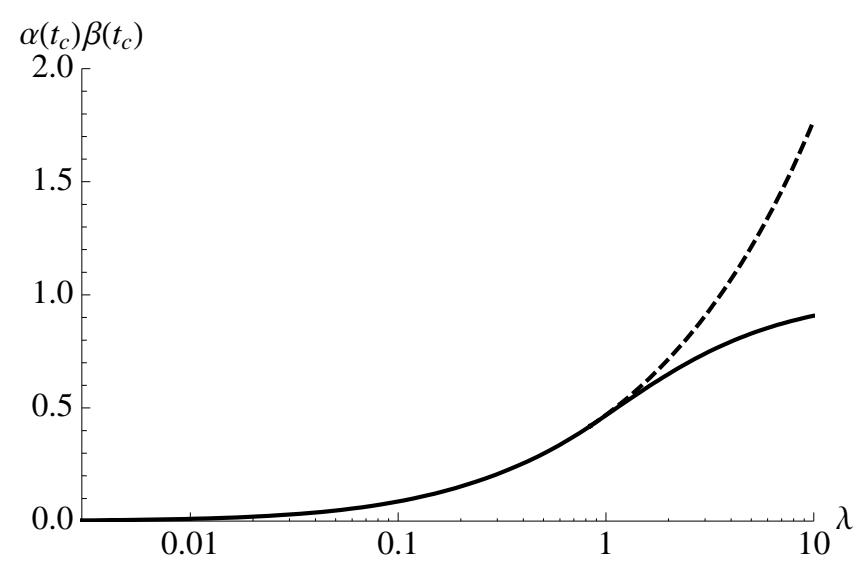

(b)

FIGURE 5: (a) the scaled time $t_{c}$ at which the carbon monoxide production rate is a maximum and (b) the corresponding scaled maximum rate of production of $\mathrm{CO}\left(\alpha\left(t_{c}\right) \beta\left(t_{c}\right)\right)$, both as a function of $\lambda$, with carbon loss control employed. The dashed curve corresponds to a case where methane flow is not turned off (same as in Figure 3).

Therefore, when $\delta \leq 0$, there is potential for zero carbon loss in the melt, if the chemical conversion is carried out for a sufficiently long time.

Plots of the scaled concentrations of carbon, metal oxide, and the rate of production of carbon monoxide are shown by the solid curves in Figure 4, where carbon loss control is implemented with $\delta=0$. Note that $\delta=0 \Rightarrow \alpha_{t_{0}}=\beta_{t_{0}}$. Thus, the methane flow is turned off beyond the time at which the curves for $\alpha$ and $\beta$ intersect. For the dashed curves in Figure 4, the methane flow is not turned off. These are the same as the curves shown in Figure 2. Comparing the solid and the dashed curves, we see that with carbon loss control, the amount of carbon remaining in the melt $(\alpha)$ is drastically reduced after the methane flow is turned off. As a consequence, the corresponding metal oxide concentration $(\beta)$ is larger than that without control of carbon loss, and it takes a longer time for the conversion to be completed. When $\lambda \leq 1$, however, the rate of production of carbon monoxide in general (proportional to $\alpha \beta$ ), and in particular the peak $\mathrm{CO}$ production rate, are not significantly affected. In contrast, when $\lambda=10$, the carbon monoxide production rate is significantly reduced when carbon loss control in implemented. The dependence of the time 
$t_{c}$ at which the $\mathrm{CO}$ production rate is a maximum, and the scaled maximum $\mathrm{CO}$ production rate $\alpha\left(t_{c}\right) \beta\left(t_{c}\right)$ on $\lambda$ are shown in Figure 5 when carbon loss control is implemented. In this figure, $t_{c}$ satisfies Equation (13) for $\lambda \leq 0.842$, and equals $\frac{1}{\lambda}$ for $\lambda>0.842$.

\subsection{Growing melt}

We now analyze a case where the melt volume increases with time. Specifically, we will permit the volume to increase as the square root of time. This would be the case when the regolith (of unbounded extent), initially at a constant temperature below its melting temperature, is heated so that its surface temperature is instantaneously raised and maintained above the melting temperature. The rate of growth of the melt volume will depend on the latent heat and other thermal properties

of the regolith. In our analysis, we will assume that the melt volume $V\left(t^{*}\right)=V_{0} \sqrt{\frac{t^{*}}{t_{0}}}$, where $V_{0}$ and $t_{0}$ are known reference values. We will assume that the surface area $A$ of the melt surface is a constant, which is valid when the heat transfer is predominantly one-dimensional. We retain all other assumptions for the chemical process discussed before.

The conservation of mass yields the following equations for the molar concentration of carbon and metal oxide in the melt.

$$
\begin{gathered}
\frac{d}{d t^{*}}\left(\sqrt{t^{*}} \alpha^{*}\right)=\frac{A \gamma C_{m} \sqrt{t_{0}}}{V_{0}}-k \sqrt{t^{*}} \alpha^{*} \beta^{*} \\
\frac{d}{d t^{*}}\left(\sqrt{t^{*}} \beta^{*}\right)=\frac{\beta_{0}}{2 \sqrt{t^{*}}}-a k \sqrt{t^{*}} \alpha^{*} \beta^{*}
\end{gathered}
$$

We will permit a time delay between the start of melt growth $\left(t^{*}=0\right)$ and the initiation of methane flow $\left(t^{*}=t_{i}\right)$. The initial conditions are $\alpha^{*}=0$ and $\beta^{*}=\beta_{0}$ at $t^{*}=t_{i}$. Dimensionless variables are defined as follows.

$$
\alpha=\frac{\alpha^{*}}{\beta_{0} / a}, \quad \beta=\frac{\beta^{*}}{\beta_{0}}, \quad p=\left(2 k \beta_{0} t^{*}\right)^{1 / 2}, \quad p_{i}=\left(2 k \beta_{0} t_{i}\right)^{1 / 2}
$$

The governing equations in terms of these variables are

$$
\frac{d}{d p}(p \alpha)=\left(2 k \beta_{0} t_{0}\right)^{1 / 2} \lambda p-p^{2} \alpha \beta
$$




$$
\begin{gathered}
\frac{d}{d p}(p \beta)=1-p^{2} \alpha \beta \\
\alpha\left(p_{i}\right)=0, \quad \beta\left(p_{i}\right)=1
\end{gathered}
$$

Equations (27) and (28) may be partially solved and written as

$$
\begin{gathered}
p \alpha=p \beta+\frac{\lambda^{\prime}}{2}\left(p^{2}-p_{i}^{2}\right)-p \\
\frac{d}{d p}(p \beta)=1-p \beta\left(p \beta+\frac{\lambda^{\prime}}{2}\left(p^{2}-p_{i}^{2}\right)-p\right)
\end{gathered}
$$

where $\lambda^{\prime}=\left(2 k \beta_{0} t_{0}\right)^{1 / 2} \lambda . \quad \lambda$ is the same parameter defined earlier (with $V_{0}$ used for the melt volume). The dimensionless parameter $k \beta_{0} t_{0}$ is the ratio of the time scale for the growth of the melt volume to the time scale for the reaction in the melt.

The instantaneous $\mathrm{CO}$ production rate is

$$
\frac{d X_{C O}}{d t^{*}}=V k \alpha^{*} \beta^{*}=\frac{V_{0} k \beta_{0}^{2}}{a\left(2 k \beta_{0} t_{0}\right)^{1 / 2}} p \alpha \beta
$$

Thus, the $\mathrm{CO}$ production rate is proportional to $p \alpha \beta$. Equation (31) for $p \beta$ is a form of the Riccati equation, but does not appear to have a closed-form solution. We have solved Equation (31) numerically. Plots of the scaled concentrations of metal oxide $(\beta)$, carbon $(\alpha)$, and the rate of production of $\mathrm{CO}(p \alpha \beta)$ are shown in Figure 6 for various values of $\lambda^{\prime}$ when the methane delay time $t_{i}=0$. A log-log scale has been used in these plots to concisely capture the various features of the curves shown. Many of the qualitative features of the curves in Figure 6 are the same as those in Figure 2 for a constant volume melt. The metal oxide concentration decreases monotonically with time. For large times, the carbon concentration increases with time because there is no carbon consumption once the metal oxide is depleted. The rate of production of $\mathrm{CO}$ is initially zero, attains a maximum at some time, and finally falls off when the metal oxide is depleted. An interesting feature in Figure 6 not present in Figure 2 is the behavior of carbon concentration with time for small values of $\lambda^{\prime}$, i.e., $\lambda^{\prime}=0.01$ and 0.1 . The carbon concentration has a local maximum and a local minimum before it increases monotonically for large values of time. This behavior may be explained as follows. Initially the carbon concentration $\alpha$ is zero. Deposition at the surface 


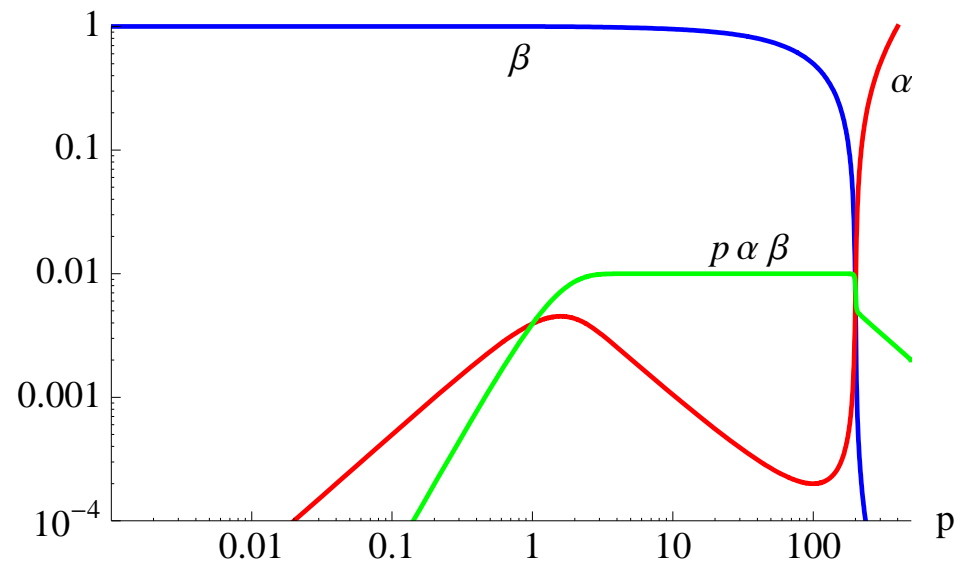

(a) $\lambda^{\prime}=0.01$

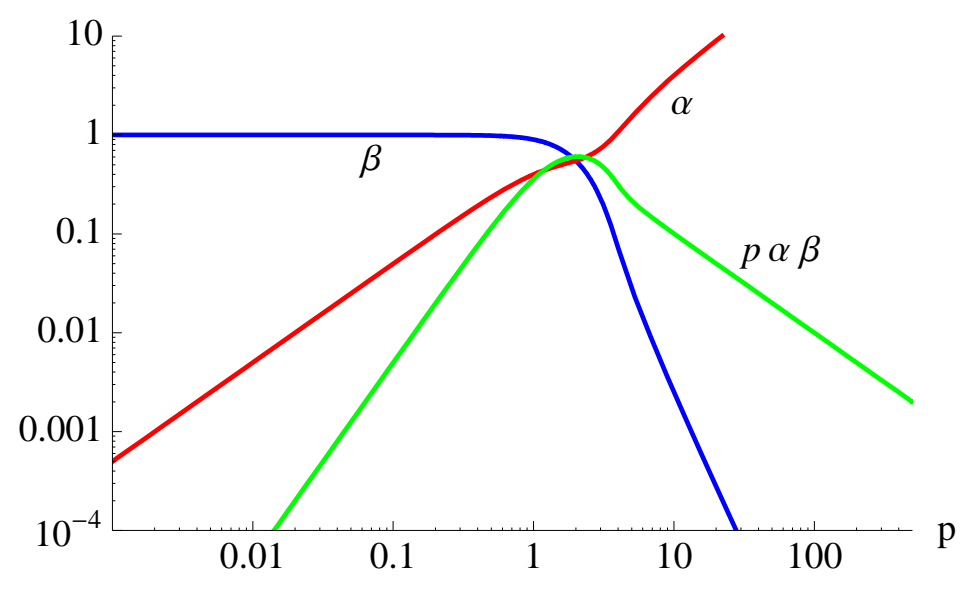

(c) $\lambda^{\prime}=1$

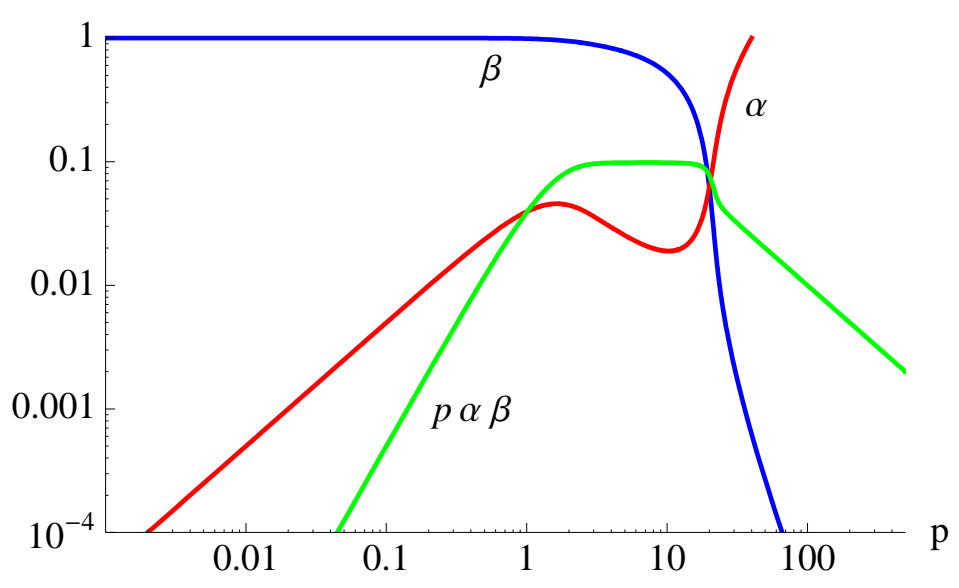

(b) $\lambda^{\prime}=0.1$

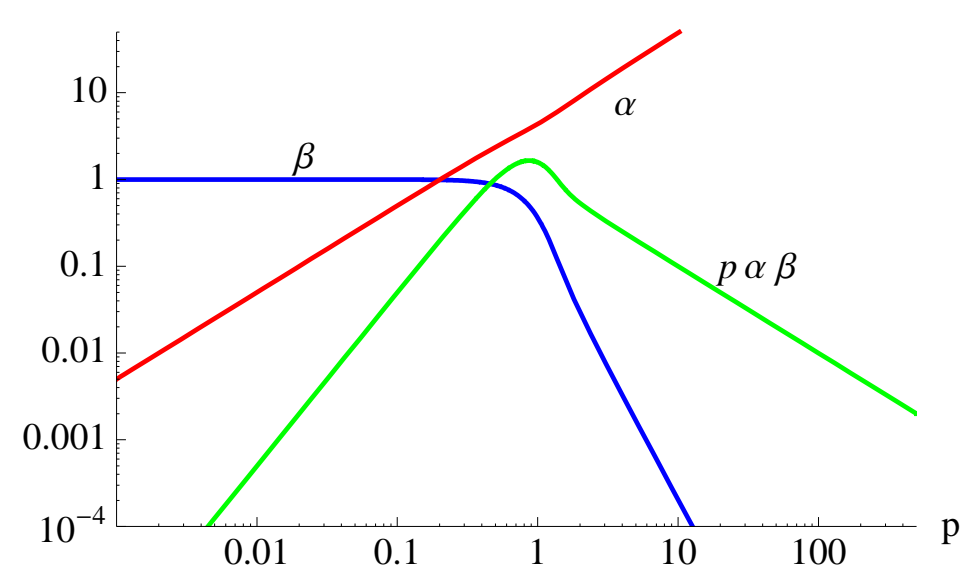

(d) $\lambda^{\prime}=10$

FIGURE 6: Case of a growing melt - Plot of the scaled concentrations of carbon $(\alpha)$ and metal oxide $(\beta)$ in the melt, and the scaled rate of production of carbon monoxide $(p \alpha \beta)$ for various values of $\lambda^{\prime}$, versus $p$ (proportional to square root of time, Eq (26)). 
tends to increase $\alpha$, while consumption due to the reaction and dilution due to increasing melt volume both tend to decrease $\alpha$. $\alpha$ would tend to increase linearly with time for a constant rate of deposition without consumption or dilution. For small time, the reaction is slow, and the constant rate of carbon deposition overpowers its dilution, as the melt volume increases at a slower rate (growing as $\sqrt{t}$ ). As time increases, the carbon consumption due to the reaction increases. Thus, $\alpha$ attains a maximum and subsequently decreases for a period of time until the reaction slows down due to metal oxide depletion. $\alpha$ thus attains a minimum. Thereafter, carbon deposition once again overpowers dilution, and $\alpha$ increases with time. Between the maximum and minimum of $\alpha$, Figure 6 shows that the rate of production of $\mathrm{CO}$ is practically constant.

When $\lambda^{\prime}$ is sufficiently large $\left(\lambda^{\prime}>1\right)$, consumption and dilution of carbon are both weak compared to its deposition, and no local extrema in $\alpha$ are present in Figure 6. Control of carbon loss in the melt, especially for large $\lambda^{\prime}$, may be implemented along the lines discussed in the previous section, if desired.

We explored the effect of delaying the initiation of methane flow, and the results are shown in Figure 7 for $\lambda^{\prime}=0.01$ and 0.1 . The maximum carbon concentration achieved after the methane flow is turned on is lowered. The longer the delay in methane flow initiation, the lower is the peak of carbon concentration. Analogous to the carbon loss strategy discussed earlier, manipulating the methane flow initiation time can be used as a method of controlling carbon build-up in the melt and possible carbon crust formation. The peak rate of production of $\mathrm{CO}$ is not affected by delaying the initiation of methane flow.

In the models that we have described above for both constant and growing melt volume, the rate constants $k$ and $\gamma$ are crucial physical properties that the model requires as input. These rate constants are not readily available in the literature and must be obtained by comparison of the model predictions with experimental results. Results from well-controlled experiments, however, do not seem to be available. Preliminary estimates $k=4.5 \times 10^{-8} \frac{\mathrm{m}^{3}}{\text { mole.s }}$ and $\gamma=0.04 \frac{\mathrm{m}}{\mathrm{s}}$ have been obtained for a lunar regolith simulant (see Balasubramaniam et al., 2009 for details) that best fit the test data obtained by ORBITEC. In these tests, however, the flow rate of methane in the gas phase 

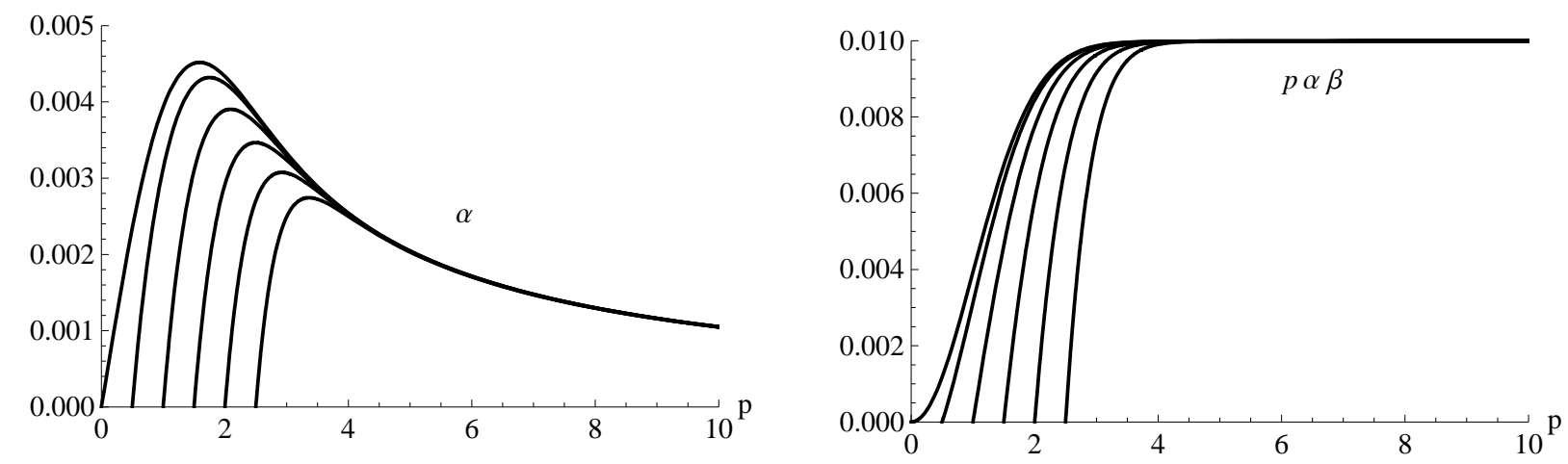

(a) $\lambda^{\prime}=0.01$
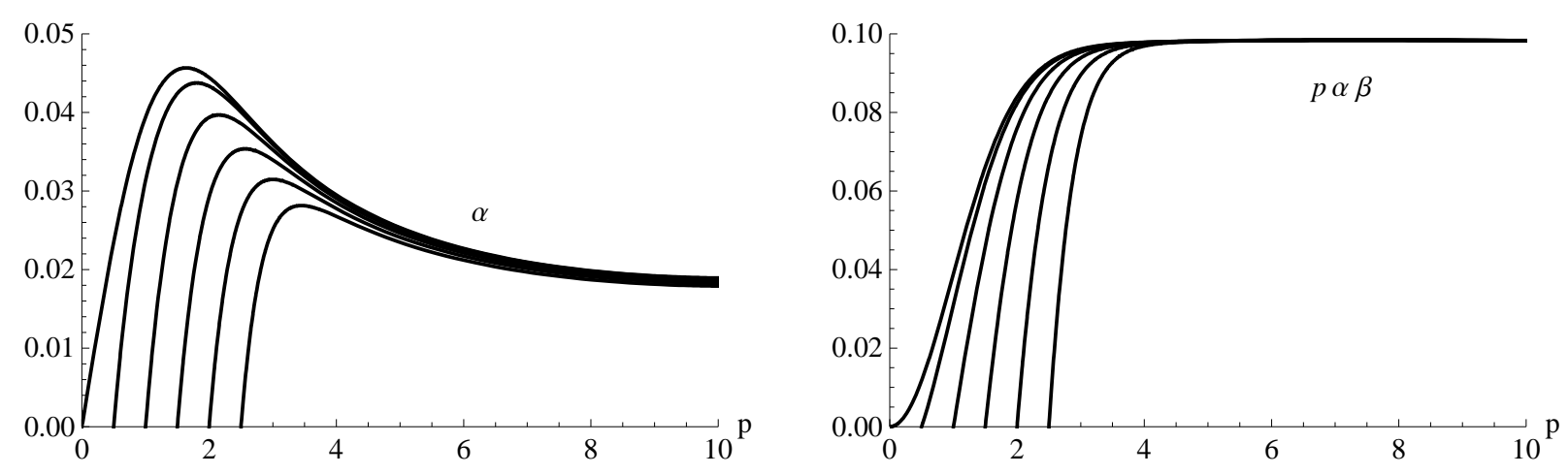

(b) $\lambda^{\prime}=0.1$

FIGURE 7: Effect of delay of methane flow initiation for a growing melt - Plot of the scaled concentrations of carbon $(\alpha)$ and the scaled rate of production of carbon monoxide $(p \alpha \beta)$ versus $p$ for $p_{i}=0,0.5,1,1.5,2,2.5$, for (a) $\lambda^{\prime}=0.01$ and (b) $\lambda^{\prime}=0.1$. For each curve, the value of $p_{i}$ corresponds to the value of $p$ at which the curve crosses the $p$ axis. 
was sufficiently low that a substantial amount of the incoming methane was pyrolyzed. Thus, the model assumption that gas phase concentration of methane at the surface can be assumed to be constant and approximated by its value at the flow inlet is questionable in these tests. These values for the rate constants must be used with caution and as preliminary estimates only.

\section{Conclusions}

We have developed a model which describes the chemical conversion of lunar regolith in a carbothermal reactor to produce carbon monoxide, and eventually oxygen. Methane flows over a molten regolith zone in the reactor continuously at a fixed temperature and pressure to maintain its concentration. Our model assumes a two-step process for the chemical conversion. First, methane is pyrolyzed as it comes in contact with the hot, molten regolith surface. The solid carbon formed after pyrolysis is deposited on the melt, and mixes with it uniformly. The second step is the reaction which takes place between carbon and the metal oxide in the melt to yield carbon monoxide that bubbles out of the melt. We considered both constant volume and growing melt cases. For a constant volume melt, our model shows that a single parameter captures the effects of melt size relative to its surface area, reaction rate constant, pyrolysis rate constant, and the concentrations of methane and metal oxide on the rate at which chemical conversion takes place in the reactor. For a growing melt, the ratio of the time scale for melt growth to the chemical time scale also appears in the dimensionless parameter. Simple strategies to control the amount of unreacted carbon in the

melt by turning the flow of methane off at a suitably chosen time, and to control the build up of carbon at the beginning of the process when the melt is growing are discussed. Rigorous validation of the model predictions with experimental results needs to be performed. 


\section{References}

Balasubramaniam, R., Gokoglu, S., and Hegde, U., "Determination of Chemical Kinetic Rate Constants of a Model for Carbothermal Processing of Lunar Regolith Simulant Using Methane," AIAA-2009-1390, 47 ${ }^{\text {th }}$ AIAA Aerospace Sciences Meeting, Orlando, Florida, January, 2009. Also NASA/TM-2009-215617, July 2009.

Gustafson, R.J., White, B.C., and Fidler, M.J., "Demonstrating Carbothermal Reduction of Lunar Regolith Using Concentrated Solar Energy," AIAA-2009-6476, AIAA SPACE 2009 Conference \& Exposition, Pasadena, California, September, 2009.

Heiken, G.H., Vaniman, D.T., and French, B.M., "Lunar sourcebook: a user's guide to the moon," Cambridge University Press, 1991.

ORBITEC, “Carbothermal Reduction of Lunar Regolith,” Phase 1 Final Report OTC-GS0167-FR06-1, Orbital Technologies Corporation (ORBITEC), Madison, Wisconsin, USA, 29 September 2006.

Rosenberg, S.D., Beegle, R.L., Jr, Guter, G.A., Miller, F.E., Rothenberg, M., “The onsite manufacture of propellant oxygen from lunar resources," In NASA. Johnson Space Center, Space Resources, Volume 3: Materials, 162-185, 1991 (SEE N93-16875 05-91).

Sanders, G.B., Larson, W.E., and Sacksteder, K.R., Mclemore, C., Johnson, K., "NASA In-Situ Resource Utilization (ISRU) Technology and Development Project Overview." Space Technology and Applications International Forum (STAIF) Conference, Albuquerque, NM, February 2008. (200800100672: (April 2008) NTRS).

Taylor, L.A. and Carrier, W.D. III, "Production of Oxygen on the Moon: Which Processes are Best and Why," AIAA Journal, 30(12), 2858-2863 (1992).

Themelis, N.J., Transport and Chemical Rate Phenomena, Gordon \& Breach Publishers, New York, NY, 1995.

Tripuraneni-Kilby, K.C., Centeno, L., Doughty, G., Mucklejohn, S., and Fray, D.J., “The Electrochemical Production of Oxygen and Metal via the FFC-Cambridge Process,"SPace Resources Roundtable VIII, Colorado School of Mines, 2006. http://www.isruinfo.com/docs/srr8/tripuraneni kilby_et_al_nov_1.zip

Wang, Y. and Yuan, Z., "Reductive kinetics of the reaction between a natural ilmenite and carbon," Int. J. Miner. Process. 81, 133-140 (2006). 


\begin{tabular}{|c|c|c|c|c|c|}
\hline \multicolumn{5}{|c|}{ REPORT DOCUMENTATION PAGE } & $\begin{array}{c}\text { Form Approved } \\
\text { OMB No. 0704-0188 }\end{array}$ \\
\hline \multicolumn{6}{|c|}{ 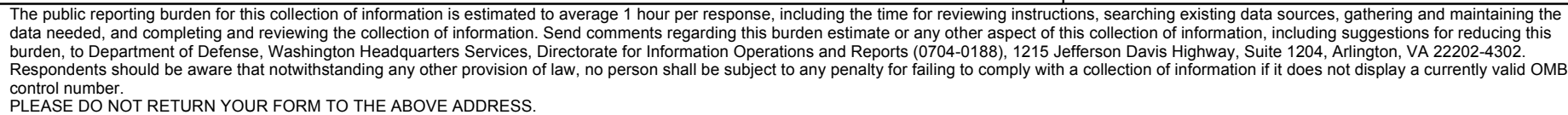 } \\
\hline \multicolumn{2}{|c|}{$\begin{array}{l}\text { 1. REPORT DATE (DD-MM-YYYY) } \\
01-11-2010\end{array}$} & \multicolumn{3}{|c|}{$\begin{array}{l}\text { 2. REPORT TYPE } \\
\text { Technical Memorandum }\end{array}$} & 3. DATES COVERED (From - To) \\
\hline \multirow{3}{*}{\multicolumn{5}{|c|}{$\begin{array}{l}\text { 4. TITLE AND SUBTITLE } \\
\text { The Reduction of Lunar Regolith by Carbothermal Processing Using Methane }\end{array}$}} & 5a. CONTRACT NUMBER \\
\hline & & & & & 5b. GRANT NUMBER \\
\hline & & & & & 5c. PROGRAM ELEMENT NUMBER \\
\hline \multirow{3}{*}{\multicolumn{5}{|c|}{$\begin{array}{l}\text { 6. AUTHOR(S) } \\
\text { Balasubramaniam, R.; Gokoglu, S., A.; Hegde, U. }\end{array}$}} & 5d. PROJECT NUMBER \\
\hline & & & & & 5e. TASK NUMBER \\
\hline & & & & & $\begin{array}{l}\text { 5f. WORK UNIT NUMBER } \\
\text { WBS } 387498.04 .01 .05 .01 .03\end{array}$ \\
\hline \multicolumn{5}{|c|}{$\begin{array}{l}\text { 7. PERFORMING ORGANIZATION NAME(S) AND ADDRESS(ES) } \\
\text { National Aeronautics and Space Administration } \\
\text { John H. Glenn Research Center at Lewis Field } \\
\text { Cleveland, Ohio 44135-3191 }\end{array}$} & $\begin{array}{l}\text { 8. PERFORMING ORGANIZATION } \\
\text { REPORT NUMBER } \\
\text { E-17503 }\end{array}$ \\
\hline \multirow{2}{*}{\multicolumn{5}{|c|}{$\begin{array}{l}\text { 9. SPONSORING/MONITORING AGENCY NAME(S) AND ADDRESS(ES) } \\
\text { National Aeronautics and Space Administration } \\
\text { Washington, DC 20546-0001 }\end{array}$}} & $\begin{array}{l}\text { 10. SPONSORING/MONITOR'S } \\
\text { ACRONYM(S) } \\
\text { NASA }\end{array}$ \\
\hline & & & & & $\begin{array}{l}\text { 11. SPONSORING/MONITORING } \\
\text { REPORT NUMBER } \\
\text { NASA/TM-2010-216927 }\end{array}$ \\
\hline \multicolumn{6}{|c|}{$\begin{array}{l}\text { 12. DISTRIBUTION/AVAILABILITY STATEMENT } \\
\text { Unclassified-Unlimited } \\
\text { Subject Categories: } 91 \text { and } 31 \\
\text { Available electronically at http://gltrs.grc.nasa.gov } \\
\text { This publication is available from the NASA Center for AeroSpace Information, 443-757-5802 }\end{array}$} \\
\hline \multicolumn{6}{|c|}{$\begin{array}{l}\text { 13. SUPPLEMENTARY NOTES } \\
\text { Submitted to the International Journal of Mineral Processing. }\end{array}$} \\
\hline \multicolumn{6}{|c|}{$\begin{array}{l}\text { The processing of lunar regolith for the production of oxygen is a key component of the In-Situ Resource Utilization (ISRU) plans currently } \\
\text { being developed by NASA. In the carbothermal process, a portion of the surface of the regolith in a container is heated by exposure to a heat } \\
\text { source so that a small zone of molten regolith is established. A continuous flow of methane is maintained over the molten regolith zone. In } \\
\text { this paper, we discuss the development of a chemical conversion model of the carbothermal process to predict the rate of production of } \\
\text { carbon monoxide. Our model is based on a mechanism where methane pyrolyzes when it comes in contact with the surface of the hot molten } \\
\text { regolith to form solid carbon hydrogen gas. Carbon is deposited on the surface of the melt, and hydrogen is released into the gas stream } \\
\text { above the melt surface. We assume that the deposited carbon mixes in the molten regolith and reacts with metal oxides in a reduction } \\
\text { reaction by which gaseous carbon monoxide is liberated. Carbon monoxide bubbles through the melt and is released into the gas stream. It is } \\
\text { further processed downstream to ultimately produce oxygen. }\end{array}$} \\
\hline \multicolumn{6}{|c|}{$\begin{array}{l}\text { 15. SUBJECT TERMS } \\
\text { Carbothermal reduction; In-Situ Resource Utilization (ISRU); Chemical kinetics; Modeling; Lunar regolith simulant; Lunar regolith; } \\
\text { Lunar simulant; Lunar exploration; Lunar science; Carbothermal processing; Pyrolysis; Kinetics }\end{array}$} \\
\hline \multicolumn{3}{|c|}{ 16. SECURITY CLASSIFICATION OF: } & $\begin{array}{l}\text { 17. LIMITATION OF } \\
\text { ABSTRACT }\end{array}$ & $\begin{array}{l}\text { 18. NUMBER } \\
\text { OF }\end{array}$ & $\begin{array}{l}\text { 19a. NAME OF RESPONSIBLE PERSON } \\
\text { STI Help Desk (email:help@sti.nasa.gov) }\end{array}$ \\
\hline $\begin{array}{l}\text { a. REPORT } \\
\text { U }\end{array}$ & $\begin{array}{l}\text { b. ABSTRACT } \\
\text { U }\end{array}$ & $\begin{array}{l}\text { c. THIS } \\
\text { PAGE } \\
\text { U }\end{array}$ & UU & $\begin{array}{l}\text { PAGES } \\
27\end{array}$ & $\begin{array}{l}\text { 19b. TELEPHONE NUMBER (include area code) } \\
443-757-5802\end{array}$ \\
\hline
\end{tabular}



